\title{
Optimizing adalimumab treatment in psoriasis with concomitant methotrexate (OPTIMAP): study protocol for a pragmatic, single-blinded, investigator-initiated randomized controlled trial
}

\author{
C. I. Busard ${ }^{1 *}$, S. P. Menting ${ }^{1+}$, J. S. van Bezooijen ${ }^{2+}$, J. M. van den Reek ${ }^{3}$, B. A. Hutten ${ }^{4}$, E. P. Prens ${ }^{2}$, E. M. de Jong ${ }^{3}$,
} M. B. van Doorn ${ }^{2}$ and P. I. Spuls ${ }^{1}$

\begin{abstract}
Background: The introduction of anti-tumor necrosis factor medications has revolutionized the treatment of psoriasis with achievement of treatment goals (Psoriasis Area and Severity Index score 75, remission) that are not usually met with conventional systemics. Nevertheless, some patients continue to experience persistent disease activity or treatment failure over time. Strategies to optimize treatment outcomes include the use of concomitant methotrexate, which has demonstrated beneficial effects on pharmacokinetics and treatment efficacy in psoriasis and other inflammatory diseases.

Methods: This is an investigator-initiated, multicenter randomized controlled trial (RCT) designed to compare the combination treatment of adalimumab and methotrexate with adalimumab monotherapy in patients with psoriasis. The primary outcome is adalimumab drug survival at week 49. Other outcomes include improvement in disease severity and quality of life, tolerability, and safety. Moreover, anti-adalimumab antibodies and adalimumab serum concentrations will be measured and correlations between genotypes and clinical outcomes will be assessed. Patient recruitment started in March 2014. Up to now, 36 patients have been randomized. Many more patients have been (pre)screened. A total of 93 patients is desired to meet an adequate sample size. In our experience, the main limitation for recruitment is prior adalimumab therapy and intolerability or toxicity for methotrexate in the past.

Discussion: OPTIMAP is the first RCT to examine combination therapy with adalimumab and methotrexate in a psoriasis population. With data derived from this study we expect to provide valuable clinical data on long-term treatment outcomes. These data will be supported by assessment of the impact of concomitant methotrexate on adalimumab pharmacokinetics. Furthermore, the influence of several single nucleotide polymorphisms on adalimumab response will be analyzed in order to support the development of a more personalized approach for this targeted therapy.
\end{abstract}

Trial registration: NTR4499. Registered on 7 April 2014.

Keywords: Multicenter, Randomized controlled trial, Pragmatic, Psoriasis, Combination therapy

\footnotetext{
* Correspondence: c.i.busard@amc.uva.nl

${ }^{\dagger}$ Equal contributors

'Department of Dermatology, Academic Medical Center, Amsterdam, The

Netherlands

Full list of author information is available at the end of the article
}

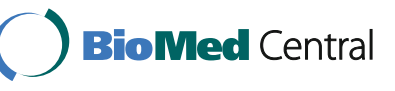

(c) The Author(s). 2017 Open Access This article is distributed under the terms of the Creative Commons Attribution 4.0 International License (http://creativecommons.org/licenses/by/4.0/), which permits unrestricted use, distribution, and reproduction in any medium, provided you give appropriate credit to the original author(s) and the source, provide a link to the Creative Commons license, and indicate if changes were made. The Creative Commons Public Domain Dedication waiver (http://creativecommons.org/publicdomain/zero/1.0/) applies to the data made available in this article, unless otherwise stated. 


\section{Background}

Adalimumab has been shown to be highly valued by patients with psoriasis due to its profound improvements in disease severity and its favorable safety profile $[1,2]$. Although its introduction (together with other anti-tumor necrosis factor (TNF) medications) has majorly advanced psoriasis care, some patients experience persistent disease activity (primary non-responders), treatment failure over time (secondary non-responders), or side effects [3-5]. Several factors have been identified to play a role in primary and secondary non-response to anti-TNFs, including pharmacokinetic factors such as the formation of antidrug antibodies (immunogenicity) and inter-individual variation in serum drug concentrations as well as pharmacogenetic factors such as the absence or presence of certain single nucleotide polymorphisms (SNPs) affecting drug metabolization $[6,7]$.

When anti-drug antibodies are formed in patients treated with an anti-TNF $\alpha$, clearance of the biologic can, to a certain extent, be accelerated depending on the concentration of the anti-drug antibodies [8]. Moreover, anti-drug antibodies can be functionally neutralizing, thereby directly affecting treatment efficacy [9]. Multiple studies observed an association between the formation of anti-adalimumab antibodies, reduced serum levels, and diminished clinical response in psoriasis and other chronic inflammatory diseases [3, 10-13]. In rheumatoid arthritis (RA) and Crohn's disease, concomitant use of methotrexate (MTX) during treatment with certain TNF $\alpha$ inhibitors (adalimumab, infliximab, and golimumab) has been demonstrated to decrease immunogenicity and significantly reduce clearance, resulting in higher systemic exposure and enhanced clinical efficacy $[11,14-18]$. Therefore, the use of combination therapy may be beneficial for successful long-term adalimumab treatment. In addition, combination therapy may enable dose reductions of individual agents, thereby decreasing toxicity and improving tolerability and compliance [19]. By targeting unregulated increased cytokine levels associated with inflammatory comorbid conditions, it is hypothesized that combination therapy may also provide a broader benefit to the patient by reducing the risk of, for example, cardiovascular events [20].

On the other hand, combination therapy may theoretically convey an increased risk for serious infections and malignancies.

Currently available evidence on anti-TNF $\alpha$ therapy with MTX in psoriasis is limited to two randomized controlled trials (RCTs) on etanercept with MTX [19, 21, 22] and a few observational studies and case series on other different anti-TNF $\alpha$ agents with MTX [23-25]. The two RCTs on etanercept and MTX provided promising results with superior efficacy of etanercept with MTX compared to etanercept monotherapy. RCTs investigating combined treatment with adalimumab and MTX are lacking $[19,26]$.

In order to investigate whether adalimumab treatment can be optimized by using concomitant MTX, long-term clinical and pharmacokinetic data on the use of adalimumab in combination with MTX are desired. Additionally, as several polymorphisms have been identified as potential predictors for anti-TNF therapy in psoriasis (e.g., TNFR1B, TNFAIP3, IL12B/IL23R) $[6,27]$ and other chronic inflammatory diseases (e.g., FcGR and ATG16L1) $[28,29]$, it will be valuable to detect genetic factors associated with response to adalimumab in order to support personalized care.

\section{Aims and objectives}

The aims and objectives of this trial are:

- To gain long-term RCT data on the efficacy and safety of adalimumab combined with MTX compared to adalimumab monotherapy

- To assess the impact of concomitant MTX on adalimumab immunogenicity and serum concentrations

- To test appropriate candidate genes and correlate genotypes with trial outcomes

\section{Methods}

This is a multicenter RCT reported according to the Standard Protocol Items: Recommendations for Interventional Trials (SPIRIT) guidelines (see Table 1 (SPIRIT table) and Additional file 1 (SPIRIT checklist)). The trial was granted ethics approval by the Academic Medical Center research ethics committee (METC 2013_346). The trial is registered at The Netherlands National Trial Register (trial number: NTR4499) and in the European Clinical Trials Database (EudraCT number: 2013004918-18). All participants will sign informed consent before participation. The study is being conducted according to the principles of the Declaration of Helsinki and in accordance with the Medical Research Involving Human Subjects Act (WMO) and other relevant guidelines, regulations, and acts.

\section{Participants}

Patients will be recruited from the outpatient clinics of the Departments of Dermatology of the Academic Medical Center (AMC) Amsterdam, Erasmus University Medical Center (EMC) Rotterdam, and the Radboud University Medical Center (RUMC) Nijmegen. Moreover, other dermatologists will be contacted to recruit and refer eligible patients to the participating centers. Participants must meet the inclusion criteria and none of the exclusion criteria (Table 2) in order to participate. 
Table 1 Timeline of the study according to the SPIRIT guidelines

\begin{tabular}{|c|c|c|c|c|c|c|c|c|}
\hline Time & Screening & $\begin{array}{l}\text { Week } \\
-2\end{array}$ & $\begin{array}{l}\text { Week } \\
-1\end{array}$ & $\begin{array}{l}\text { Week } \\
0\end{array}$ & $\begin{array}{l}\text { Week } \\
3\end{array}$ & $\begin{array}{l}\text { Week } \\
5\end{array}$ & $\begin{array}{l}\text { Every } 12 \text { weeks } \\
\text { from week } 13 \\
\text { up to week } 145\end{array}$ & $\begin{array}{l}\text { Early } \\
\text { termination }\end{array}$ \\
\hline \multicolumn{9}{|l|}{ Enrollment } \\
\hline Informed consent & $x$ & & & & & & & \\
\hline Demography, medical history & $x$ & & & & & & & \\
\hline Vital signs and full physical examination & $x$ & & & $x$ & & $x$ & $x$ & $x$ \\
\hline Psoriasis Area and Severity Index (PASI) & $x$ & & & $x$ & & $x$ & $x$ & $x$ \\
\hline Eligibility criteria & $x$ & & & & & & & \\
\hline Laboratory assessments & $x$ & & $x$ & $x$ & $x$ & $x$ & $x$ & $x$ \\
\hline $\begin{array}{l}\text { Chest } \mathrm{X} \text {-ray, Mantoux test, and interferon-gamma release } \\
\text { assay (IGRA) }\end{array}$ & $x$ & & & & & & & \\
\hline Randomization & $x$ & & & & & & & \\
\hline \multicolumn{9}{|l|}{ Intervention } \\
\hline \multicolumn{2}{|l|}{ Adalimumab (Humira) + MTX } & $X(\mathrm{MTX})$ & X (MTX) & \multicolumn{5}{|c|}{ X (Humira + MTX) } \\
\hline \multicolumn{4}{|l|}{ Humira monotherapy } & \multicolumn{5}{|c|}{ X (Humira) } \\
\hline \multicolumn{9}{|l|}{ Assessments } \\
\hline Laboratory assessments & $x$ & & $x$ & $x$ & $x$ & $x$ & $x$ & $x$ \\
\hline PASI & $x$ & & & $x$ & & $x$ & $x$ & $x$ \\
\hline Physician global assessment & $x$ & & & $x$ & & $x$ & $x$ & $x$ \\
\hline Patient global assessment & $x$ & & & $x$ & & $x$ & $x$ & $x$ \\
\hline $\begin{array}{l}\text { Impact on quality of life (Skindex } 29 \text { and Dermatology Life } \\
\text { Quality Index (DLQI)) }\end{array}$ & $x$ & & & $x$ & & $x$ & $x$ & $x$ \\
\hline Prior or concomitant therapy & $x$ & & & $x$ & & $x$ & $x$ & $x$ \\
\hline Adverse events & $x$ & & & $x$ & & $x$ & $x$ & $x$ \\
\hline Drug adherence & & & & $x$ & & $x$ & $x$ & $x$ \\
\hline
\end{tabular}

These criteria will be assessed at the screening visit. Potential participants who are deemed ineligible at screening will be allowed a second screening visit if the reason for ineligibility is a temporary status (e.g., latent tuberculosis).

Table 2 Eligibility criteria

\begin{tabular}{ll}
\hline Inclusion & Exclusion \\
\hline$\geq 18$ years & History of significant MTX toxicity, \\
$\begin{array}{l}\text { Diagnosis of moderate to severe } \\
\text { plaque psoriasis (PASI } \geq 8)\end{array}$ & intolerability, or contraindication \\
Adalimumab naïve & Known liver or kidney malfunction \\
Candidate for biologic therapy & Alcohol abuse \\
Willing and able to use adequate & Bone marrow hypoplasia, \\
contraceptives during the study & leukocytopenia, thrombocytopenia, \\
& Known severe or chronic infections \\
& like tuberculosis or HIV \\
& Ulcers in the oral cavity or known \\
& active ulcers in digestive tract \\
& Pregnant or nursing women \\
& Need for live vaccinations \\
& Use of other immunosuppressive \\
& medication (e.g., prednisone, \\
& mycophenolate mofetil (Cellcept), \\
& cyclosporine (Neoral), sirolimus \\
& (Rapamune), systemic tacrolimus \\
& (Prograf)) \\
\hline
\end{tabular}

\section{Interventions}

All patients receive adalimumab $40 \mathrm{mg}$ subcutaneously every other week starting 1 week after a loading dose of $80 \mathrm{mg}$ and will be randomized 1:1 to receive either oral MTX $10 \mathrm{mg}$ weekly (combination group) or no addition of MTX (monotherapy group). MTX therapy will be initiated 2 weeks prior to adalimumab therapy, and administration will be followed by folic acid $5 \mathrm{mg}$ 24 hours after MTX intake (see Table 1).

In case of MTX toxicity (e.g., liver toxicity or leukopenia) or intolerability, dosing can be paused (for a maximum of 2 weeks up to four times during the entire study), or the dose can be adjusted to $7.5 \mathrm{mg}$. Moreover, patients are allowed to switch from oral to subcutaneous administration. In case of adalimumab toxicity or intolerability, dosing can be paused (for a maximum of 2 weeks up to four times during the entire study).

Throughout the study, no systemic anti-psoriatic drugs are allowed for treatment other than the study medication (Table 3). If medically necessary (i.e., to control intolerable psoriasis activity), rescue treatment with topical corticosteroids, vitamin D derivates (calcipotriol/betamethasone 
Table 3 Wash-out periods

\begin{tabular}{ll}
\hline Therapy & Wash-out period \\
\hline Topical therapy & 2 weeks \\
Phototherapy & 2 weeks \\
Conventional systemic therapy/etanercept & 4 weeks \\
Infliximab/ustekinumab & 6 weeks \\
\hline
\end{tabular}

or calcitriol), or calcineurin inhibitors may be provided to study patients at the discretion of the investigator after baseline and through week 145 (end of study) (Table 4).

\section{Randomization and blinding}

Consecutive patients will be prospectively enrolled and randomly assigned if eligible to either the intervention (adalimumab with MTX) or control (adalimumab monotherapy) group after obtaining informed consent. Each consecutive patient will be assigned a randomization number according to a computer-generated randomization list (ALEA) using random block sizes of 2, 4, 6, and 8 to ensure allocation concealment. Randomization is stratified for TNF $\alpha$-blocker exposure status to achieve balance with regard to prior TNFa-blocker exposure in the study population.

This is an observer-blinded study. The observer (outcome assessor) will perform clinical outcome assessments of disease severity (Psoriasis Area and Severity Index (PASI) and investigator global assessment (IGA)) at each study visit. The clinician performs all other study procedures and is not blinded. Both clinician and participant know the treatment allocation; as such, no special measures are required to allow for breaking of treatment codes. However, treatment allocation will not be revealed to the recruiting physician until participants' details and key stratification variables have been irrevocably entered onto the web-based randomization site.

\section{Endpoints}

The primary outcome is adalimumab drug survival (number of patients still on adalimumab treatment) at week 49.

Secondary outcomes are the following:

- Adalimumab drug survival (number of patients still on adalimumab treatment) at week 145

- Proportion of patients who reach treatment goals ${ }^{1}$ at week 13 , week 25 , week 49 , and week 145

Table 4 Allowed escape medication

\begin{tabular}{ll}
\hline $\begin{array}{l}\text { Scalp/palms/ } \\
\text { soles }\end{array}$ & $\begin{array}{l}\text { Low or high potency corticosteroids, calcitriol/ } \\
\text { calcipotriol, or a combination }\end{array}$ \\
$\begin{array}{l}\text { Face and } \\
\text { body }\end{array}$ & Low potency corticosteroids, calcitriol/calcipotriol, or \\
inverse & topical tacrolimus $0.1 \%$ or $0.03 \%$ \\
psoriasis & Topical tacrolimus $0.1 \%$ or $0.03 \%$ \\
\hline
\end{tabular}

- Proportion of patients achieving PASI 75 at weeks 49 and 145

- Proportion of patients achieving IGA clear or almost clear at weeks 49 and 145

- Mean improvement in PASI at weeks 49 and 145

- Proportion of patients with PGA clear or almost clear at weeks 49 and 145

- Mean improvement in Dermatology Life Quality Index (DLQI) and Skindex at weeks 49 and 145

- Proportion of patients with (serious) adverse events at weeks 49 and 145

- Proportion of patients with changes in laboratory assessments at weeks 49 and 145

- Proportion of patients with (no, low, or high) levels of antibodies at weeks 49 and 145

- Median adalimumab trough concentrations (mg/L) at weeks 49 and 145

- Correlation between genetic polymorphisms and adalimumab response

\section{Procedures and assessments}

Patients will visit the outpatient clinic at screening, baseline, week 5 , week 13 , and every 12 weeks thereafter until study completion (weeks 25, 37, 49, 61, 73, 85, 97, $109,121,133,145$ ) (Table 1). A variety of parameters will be collected during each visit to assess efficacy, including physician- (PASI/IGA (static; scale 0-4 [30])) and patient-reported (patient-reported global assessment (PGA static; scale 0-4)) outcomes. Quality of life assessment will be performed using Skindex and DLQI questionnaires. Safety will be assessed by evaluating the incidence of (serious) adverse events, obtaining a detailed medical history, thorough physical examination, vital signs, clinical laboratory testing, and urinalysis (including pregnancy tests for females of childbearing potential at screening). Concomitant medication and medical procedures will be collected from obtainment of informed consent up to end of study. Patients will receive a diary in which they will register the administration dates of adalimumab (and MTX in the combination group), any changes in their health status, and/or changes in concomitant medication used. The local investigator reviews the diary to determine drug adherence and the incidence and type of adverse events. An independent Data Safety Monitoring Board (DSMB) has been established to review efficacy and safety data periodically in an unblinded fashion.

\section{Laboratory testing}

Blood samples will be collected at each visit (serum samples are collected just before administration of adalimumab (3-day window) to ensure accurate determination of serum through levels) to monitor drug safety, to determine immunogenicity against adalimumab, and to 
measure adalimumab serum through levels. Samples for serum preparation are kept at room temperature for 1-2 hours for coagulation, followed by centrifugation at 3000 RPM for 15 minutes at room temperature. Supernatant is collected, aliquoted, and stored at $-20{ }^{\circ} \mathrm{C}$ until further use. Adalimumab serum through levels will be determined using a non-commercial enzyme-linked immunosorbent assay (ELISA, Sanquin, Amsterdam, The Netherlands). Detection of anti-adalimumab antibodies will be performed through a radioimmunoassay (Sanquin). The antibody test will be considered positive when the antibody concentration exceeds $12 \mathrm{AU} / \mathrm{mL}$. Concentrations between 12 and $100 \mathrm{AU} / \mathrm{mL}$ will be considered low antibody titers; those above $100 \mathrm{AU} / \mathrm{mL}$ will be considered high antibody titers [3].

Additionally, a single blood sample will be collected at screening from which DNA will be collected and stored at $-80{ }^{\circ} \mathrm{C}$. As scientific interest in this field is currently increasing, DNA analysis will be performed based upon accumulating data acquired from (ongoing) pharmacogenetic studies.

\section{Justification of sample size}

A total of 84 patients (randomized 1:1 to concomitant MTX or no MTX) will give the study at least $80 \%$ power at a 0.05 two-sided significance level using a two-sample chi-squared test to detect a difference of $28 \%$ in drug survival at week 49 . We aim to enroll 93 patients to allow for an approximate 10\% loss to follow-up. These calculations were performed using Nquery 6.0.2. Due to the lack of data in a psoriasis population, the expected clinically relevant difference in drug survival between both treatment groups was hypothesized based on studies performed in patients with RA. The prevalence of (clinically relevant) anti-drug antibody formation is estimated to be $45 \%$ in patients on adalimumab monotherapy (a similar percentage is found in patients with psoriasis [31] and around $17 \%$ in patients on adalimumab with low-dose (5-10 mg) MTX after 49 weeks [32]. A clear correlation between antibody formation and treatment failure (with subsequent treatment discontinuation) in patients on adalimumab has been demonstrated [31]. Based on these data, drug survival is estimated to be $83 \%$ (100 minus 17) for the experimental group and $55 \%$ (100 minus 45 ) for the control group after 49 weeks of follow-up.

\section{Statistical analysis}

The primary analysis will be conducted on the intention-to-treat population, including all randomized participants in the groups to which they were randomized. A per-protocol population (excluding major protocol violations) will be used to check the robustness of the primary analyses. The safety population will consist of all patients receiving at least one dose of the study drug.

Adverse events will be coded according to the Medical Dictionary for Regulatory Activities (MedDRA) adverse event classification. The overall incidence of (serious) adverse events and number and proportion of patients reporting such events will be summarized by treatment group.

Differences in dichotomous outcomes among the two study groups will be analyzed using the chisquared test or Fisher's exact test when the expected cell frequencies fall below 5 . We will express differences in drug survival as absolute differences and relative risks, with associated 95\% confidence intervals, with the group on adalimumab monotherapy as the reference. In case patients are lost to follow-up during the study period, we will analyze these data by means of survival analysis. We will construct cumulative survival curves (Kaplan-Meier method) for the treatment groups, and these curves will be compared using the log-rank test. One-way analysis-of-variance statistics will be calculated to compare continuous outcome measures between groups.

There are no formal planned interim analyses, but progress reports on all data issues are presented to the DSMB.

\section{Trial status}

Patient recruitment started in March 2014 and is currently ongoing. Based on our experience so far, recruitment is limited by two main factors: prior use of adalimumab and intolerability or toxicity for MTX in the past.

Moreover, disease activity in patients who are transitioned from another biologic is often suppressed $(<\mathrm{PASI}$ $8)$. To enlarge the geographical area in which patients can participate in the study and to enhance patient recruitment, three additional hospitals have been activated for patient recruitment: Amphia Hospital (Breda) and Bravis Hospital (Bergen op Zoom) in The Netherlands and Ghent University Hospital in Belgium.

\section{Discussion}

Although combination treatment with anti-TNFs and MTX is being prescribed for psoriasis in clinical practice, available evidence and guidance on the use of combination treatment is limited. No consensus about certain treatment aspects such as timing of initiation of MTX (prior to anti-TNF or during anti-TNF therapy) and MTX dosing exists. Therefore, besides the rationale for our primary endpoints, we would like to emphasize the choice of dosing and initiation of comedication for the current RCT. 


\section{Primary endpoint}

In this study, drug survival after 49 weeks of treatment is chosen as the primary endpoint. Based on currently available evidence, response rates to anti-TNFs in patients with and without concomitant MTX may remain similar; however, drug survival is often superior in patients receiving comedication compared to monotherapy, and this difference tends to be more prominent than differences in response rates [33-36]. Moreover, by categorizing reasons for treatment discontinuation (lack of efficacy, safety concerns), several important treatment aspects are being combined.

\section{Initiation of MTX prior to adalimumab therapy}

Concomitant use of MTX has been demonstrated to significantly reduce the clearance of adalimumab, resulting in higher adalimumab trough levels in patients with RA $[14,37]$. However, it takes time for MTX to exert a full effect on the pharmacokinetics of adalimumab [37]. The slow onset of drug action of MTX can be attributed to an intracellular accumulation process [38, 39]. After MTX uptake into cells, it is converted to MTX polyglutamates, active metabolites which are believed to exert the antiinflammatory actions of MTX. The current product label for adalimumab indicates that MTX decreases the apparent clearance of adalimumab after single and multiple doses by $29 \%$ and $44 \%$, respectively [37].

In order to ensure maximal potential for MTX to exert a beneficial effect on adalimumab pharmacokinetics from the start on, MTX therapy is initiated 2 weeks before administration of adalimumab in the intervention group.

\section{Choice of MTX dosing}

The dose of MTX as monotherapy can range from 7.5 to $25 \mathrm{mg} /$ week, depending on national guidelines and patient/physician's preference. A systematic literature review of MTX monotherapy has recommended initial treatment with $10-15 \mathrm{mg}$ orally with dose increases to $20 \mathrm{mg} /$ week if needed and tolerated [40]. Available evidence suggests that MTX toxicity is dose-dependent and low-dose MTX monotherapy treatment can be effective. However, no RCTs have explored the minimally effective dose of MTX in a group of patients when used in combination with a TNF $\alpha$ inhibitor. This dose may differ from minimally effective monotherapy doses.

MTX tends to reduce immunogenicity and increase adalimumab serum levels in a dose-dependent manner in patients with RA. Results indicate a (non-significant) increase in adalimumab serum concentrations with higher doses of MTX (10-20 mg) compared to low-dose MTX. However, a dose of 5-10 mg of concomitant MTX seems already sufficient to substantially decrease immunogenicity against adalimumab and maintain serum concentrations within the therapeutic range [32, 41]. In the treatment of psoriasis, MTX $10 \mathrm{mg}$ per week is an accepted dose for treating psoriasis according to (inter)national guidelines [40]. In order to avoid an increased risk of side effects like hepatotoxicity, a dosage of $10 \mathrm{mg} \mathrm{MTX/week} \mathrm{is} \mathrm{chosen} \mathrm{in} \mathrm{our} \mathrm{RCT} \mathrm{over} \mathrm{a} \mathrm{higher}$ dose.

With this RCT we aim to improve the body of evidence on efficacy and safety of adalimumab and MTX combination treatment in order to investigate whether MTX can optimize adalimumab treatment. Moreover, with the analysis of pharmacogenetic data, we hope to support personalized medicine and more accurate prediction of treatment response.

\section{Study strengths and limitations}

This study represents the first RCT on combined treatment with adalimumab and methotrexate. Data will be extracted and analyzed independent of industry. It is an observer-blinded study with concealment of allocation. Clinical as well as pharmacokinetic and pharmacogenetic outcomes will be assessed in the short and long term.

However, some limitations apply. Due to the pragmatic study design, the trial is not conducted as double-blind. Moreover, the sample size limits assessment of the predictive performance of genetic polymorphisms on clinical and pharmacokinetic outcomes. Optimal dosing and timing of MTX comedication are not evaluated in this study and will have to be investigated in future research.

\section{Endnotes}

${ }^{1}$ Treatment goals will be achieved if patients reach PASI $\geq 75$ or PASI $\geq 50$ in combination with DLQI $\leq 5$. Treatment goals will not be achieved if PASI $<50$ or PASI $\geq 50<75$ in combination with DLQI $\geq 5$ [42].

\section{Additional file}

Additional file 1: SPIRIT 2013 checklist: recommended items to address in a clinical trial protocol and related documents.* (DOC $121 \mathrm{~kb}$ )

\section{Abbreviations \\ DLQI: Dermatology Life Quality Index; DSMB: Data Safety Monitoring Board MTX: Methotrexate; PASI: Psoriasis Area and Severity Index; RA: Rheumatoid arthritis; RCT: Randomized controlled trial; SNP: Single nucleotide polymorphism; TNF: Tumor necrosis factor}

\section{Acknowledgements}

We would like to thank Jo Lambert (UZ Gent (Belgium)), Wim de Kort (Amphia Hospital Breda (Netherlands)), Milan Tijoe (Bravis Hospital Bergen op Zoom (Netherlands)), and their team members for their enthusiasm and commitment in participating in the study as recruiting centers.

Funding

This randomized controlled trial is conducted without funding. 


\section{Availability of data and materials}

The datasets used and/or analyzed during the current study are available from the corresponding author on reasonable request.

\section{Authors' contributions}

$P S, M D, E J$, and EP are the principal investigators. All authors contributed to the design and development of the study protocol. SM and CB were responsible for conceiving ethics approval and writing the protocol. SB, MD, and EP were involved in the development of the data management system, and JR and EJ organized and coordinated study monitoring. $\mathrm{BH}$ (trial statistician) was involved in the data analysis plan. CB wrote the first draft of this paper; all authors commented and critically reviewed drafts of the paper. All authors read and approved the final manuscript.

\section{Competing interests}

PS performed consultancies for LEO Pharma, AbbVie, and Novartis and received an independent research grant from Schering-Plough and LEO Pharma. She is involved in performing clinical trials with many pharmaceutical industries that manufacture drugs used for the treatment of psoriasis. EJ has received research grants from AbbVie, Pfizer, and Janssen. She has acted as consultant and/or paid speaker for and/or participated in research sponsored by companies that manufacture drugs used for the treatment of psoriasis including AbbVie, Janssen, MSD, Pfizer, Novartis, Eli Lilly, Amgen, and Cellgene. The obtained resources are not personal but go to the independent research fund of the Department of Dermatology of Radboud University Mmedical Centre Nijmegen, The Netherlands.

JR performed clinical trials for AbbVie and Janssen and has received speaking fees from AbbVie and Eli Lilly and reimbursement for attending a symposium from Janssen, Pfizer, and AbbVie. Fees were paid directly to the institution.

EP has acted as a consultant for AbbVie, Amgen, AstraZeneca, Baxter, Eli Lilly, Galderma, Janssen-Cilag, Novartis, and Pfizer and has received investigatorinitiated research grants from Pfizer, Janssen-Cilag, and AbbVie. MD has acted as a consultant for Abbott, Janssen, LEO Pharma, and Pfizer and has been an investigator for Eli Lilly, Idera Pharmaceuticals, and Novartis. All other authors declare that they have no competing interests.

\section{Consent for publication}

The signed Informed Consent Form will be obtained by the investigator prior to inclusion in the study and scientific use of acquired data.

\section{Ethics approval and consent to participate}

The clinical investigation will be conducted in compliance with applicable international standards and regulatory requirements, as well as with the ethical principles of the latest revision of the Declaration of Helsinki as adopted by the World Medical Association. The study received approval by the ethics committee of the Academic Medical Center Amsterdam, The Netherlands (committee reference number 2013_346). The signed Informed Consent Form will be obtained by the investigator prior to inclusion in the study.

\section{Trial status}

Recruitment of patients started in March 2014.

\section{Author details}

'Department of Dermatology, Academic Medical Center, Amsterdam, The Netherlands. ${ }^{2}$ Department of Dermatology, Erasmus University Medical Center, Rotterdam, The Netherlands. ${ }^{3}$ Department of Dermatology, Radboud University Medical Center, Nijmegen, The Netherlands. ${ }^{4}$ Department of Clinical Epidemiology, Biostatistics and Bioinformatics, Academic Medical Center, Amsterdam, The Netherlands.

Received: 26 July 2016 Accepted: 2 January 2017 Published online: 02 February 2017

\section{References}

1. Saurat JH, Stingl G, Dubertret L, Papp K, Langley RG, Ortonne JP, et al. Efficacy and safety results from the randomized controlled comparative study of adalimumab vs. methotrexate vs. placebo in patients with psoriasis (CHAMPION). Br J Dermatol. 2008;158(3):558-66.
2. van den Reek JM, van Luumig PP, Otero ME, Zweegers J, van de Kerkhof PC, Ossenkoppele PM, et al. Satisfaction of treatment with biologics is high in psoriasis: results from the Bio-CAPTURE network. Br J Dermatol. 2014;170(5): 1158-65.

3. Menting SP, van Lumig PP, de Vries AC, van den Reek JM, van der Kleij D, de Jong EM, et al. Extent and consequences of antibody formation against adalimumab in patients with psoriasis: one-year follow-up. JAMA Dermatol. 2014;150(2):130-6.

4. Warren RB, Smith $\mathrm{CH}$, Yiu ZZ, Ashcroft DM, Barker JN, Burden AD, et al. Differential drug survival of biologic therapies for the treatment of psoriasis: a prospective observational cohort study from the British Association of Dermatologists Biologic Interventions Register (BADBIR). J Invest Dermatol. 2015;135(11):2632-40.

5. Bito T, Nishikawa R, Hatakeyama M, Kikusawa A, Kanki H, Nagai H, et al. Influence of neutralizing antibodies to adalimumab and infliximab on the treatment of psoriasis. Br J Dermatol. 2014;170(4):922-9.

6. Prieto-Perez R, Cabaleiro T, Dauden E, Abad-Santos F. Gene polymorphisms that can predict response to anti-TNF therapy in patients with psoriasis and related autoimmune diseases. Pharmacogenomics J. 2013;13(4):297-305.

7. Coto-Segura P, Batalla A, Gonzalez-Fernandez D, Gomez J, Santos-Juanes J, Queiro $R$, et al. CDKAL1 gene variants affect the anti-TNF response among psoriasis patients. Int Immunopharmacol. 2015;29(2):947-9.

8. Xu Z, Davis HM, Zhou H. Clinical impact of concomitant immunomodulators on biologic therapy: pharmacokinetics, immunogenicity, efficacy and safety. J Clin Pharmacol. 2015;55 Suppl 3:S60-74.

9. van Schouwenburg PA, van de Stadt LA, de Jong RN, van Buren EE, Kruithof $\mathrm{S}$, de Groot $\mathrm{E}$, et al. Adalimumab elicits a restricted anti-idiotypic antibody response in autoimmune patients resulting in functional neutralisation. Ann Rheum Dis. 2013;72(1):104-9.

10. Bartelds GM, Krieckaert CL, Nurmohamed MT, van Schouwenburg PA, Lems WF, Twisk JW, et al. Development of antidrug antibodies against adalimumab and association with disease activity and treatment failure during long-term follow-up. JAMA. 2011;305(14):1460-8.

11. Bartelds GM, Wijbrandts CA, Nurmohamed MT, Stapel S, Lems WF, Aarden L et al. Clinical response to adalimumab: relationship to anti-adalimumab antibodies and serum adalimumab concentrations in rheumatoid arthritis. Ann Rheum Dis. 2007;66(7):921-6.

12. Radstake TR, Svenson M, Eijsbouts AM, van den Hoogen FH, Enevold C, van Riel PL, et al. Formation of antibodies against infliximab and adalimumab strongly correlates with functional drug levels and clinical responses in rheumatoid arthritis. Ann Rheum Dis. 2009;68(11):1739-45.

13. West RL, Zelinkova Z, Wolbink GJ, Kuipers EJ, Stokkers PC, van der Woude CJ. Immunogenicity negatively influences the outcome of adalimumab treatment in Crohn's disease. Aliment Pharmacol Ther. 2008;28(9):1122-6.

14. Zhuang $Y, X u$ Z, Frederick B, de Vries DE, Ford JA, Keen M, et al. Golimumab pharmacokinetics after repeated subcutaneous and intravenous administrations in patients with rheumatoid arthritis and the effect of concomitant methotrexate: an open-label, randomized study. Clin Ther. 2012;34(1):77-90.

15. Baert F, Noman M, Vermeire S, Van Assche G, D' Haens G, Carbonez A, et al. Influence of immunogenicity on the long-term efficacy of infliximab in Crohn's disease. N Engl J Med. 2003;348(7):601-8.

16. Pouw MF, Krieckaert CL, Nurmohamed MT, van der Kleij D, Aarden L, Rispens $T$, et al. Key findings towards optimising adalimumab treatment: the concentration-effect curve. Ann Rheum Dis. 2015;74(3):513-8.

17. Kuriya B, Arkema EV, Bykerk VP, Keystone EC. Efficacy of initial methotrexate monotherapy versus combination therapy with a biological agent in early rheumatoid arthritis: a meta-analysis of clinical and radiographic remission. Ann Rheum Dis. 2010;69(7):1298-304.

18. Weisman MH, Moreland LW, Furst DE, Weinblatt ME, Keystone EC, Paulus $H E$, et al. Efficacy, pharmacokinetic, and safety assessment of adalimumab, a fully human anti-tumor necrosis factor-alpha monoclonal antibody, in adults with rheumatoid arthritis receiving concomitant methotrexate: a pilot study. Clin Ther. 2003;25(6):1700-21.

19. Busard C, Zweegers J, Limpens J, Langendam M, Spuls PI. Combined use of systemic agents for psoriasis: a systematic review. JAMA Dermatol. 2014; 150(11):1213-20.

20. Hugh J, Van Voorhees AS, Nijhawan RI, Bagel J, Lebwohl M, Blauvelt A, et al. From the Medical Board of the National Psoriasis Foundation: the risk of cardiovascular disease in individuals with psoriasis and the potential impact of current therapies. J Am Acad Dermatol. 2014;70(1):168-77. 
21. Gottlieb AB, Langley RG, Strober BE, Papp KA, Klekotka P, Creamer K, et al. A randomized, double-blind, placebo-controlled study to evaluate the addition of methotrexate to etanercept in patients with moderate to severe plaque psoriasis. Br J Dermatol. 2012;167(3):649-57.

22. Zachariae C, Mork NJ, Reunala T, Lorentzen H, Falk E, Karvonen SL, et al. The combination of etanercept and methotrexate increases the effectiveness of treatment in active psoriasis despite inadequate effect of methotrexate therapy. Acta Derm Venereol. 2008;88(5):495-501.

23. Dalaker $\mathrm{M}$, Bonesronning $\mathrm{JH}$. Long-term maintenance treatment of moderate-to-severe plaque psoriasis with infliximab in combination with methotrexate or azathioprine in a retrospective cohort. J Eur Acad Dermatol Venereol. 2009;23(3):277-82.

24. van den Reek JM, van Lumig PP, Kievit W, Zweegers J, van de Kerkhof PC, Seyger MM, et al. Effectiveness of adalimumab dose escalation, combination therapy of adalimumab with methotrexate, or both in patients with psoriasis in daily practice. J Dermatolog Treat. 2013;24(5):361-8.

25. Driessen RJ, van de Kerkhof PC, de Jong EM. Etanercept combined with methotrexate for high-need psoriasis. Br J Dermatol. 2008;159(2):460-3.

26. van Bezooijen JS, Prens EP, Pradeepti MS, Atiqi R, Schreurs MW, Koch BC, et al. Combining biologics with methotrexate in psoriasis: a systematic review. $\mathrm{Br} J$ Dermatol. 2015;172(6):1676-80.

27. Gallo E, Cabaleiro T, Roman M, Solano-Lopez G, Abad-Santos F, Garcia-Diez A et al. The relationship between tumour necrosis factor (TNF)-alpha promoter and IL12B/IL-23R genes polymorphisms and the efficacy of anti-TNF-alpha therapy in psoriasis: a case-control study. Br J Dermatol. 2013;169(4):819-29.

28. Koder S, Repnik K, Ferkolj I, Pernat C, Skok P, Weersma RK, et al. Genetic polymorphism in ATG16L1 gene influences the response to adalimumab in Crohn's disease patients. Pharmacogenomics. 2015;16(3):191-204.

29. Davila-Fajardo CL, van der Straaten T, Baak-Pablo R, Medarde Caballero C, Cabeza Barrera J, Huizinga TW, et al. FCGR genetic polymorphisms and the response to adalimumab in patients with rheumatoid arthritis. Pharmacogenomics. 2015;16(4):373-81.

30. Langley RG, Feldman SR, Nyirady J, van de Kerkhof P, Papavassilis C. The 5-point Investigator's Global Assessment (IGA) scale: a modified tool for evaluating plaque psoriasis severity in clinical trials. J Dermatolog Treat. 2015;26(1):23-31.

31. Menting SP, van den Reek JM, Baerveldt EM, de Jong EM, Prens EP, Lecluse LL, et al. The correlation of clinical efficacy, serum trough levels and antidrug antibodies in ustekinumab-treated patients with psoriasis in a clinical-practice setting Br J Dermatol. 2015;173(3):855-7.

32. Krieckaert CL, Nurmohamed MT, Wolbink GJ. Methotrexate reduces immunogenicity in adalimumab treated rheumatoid arthritis patients in a dose dependent manner. Ann Rheum Dis. 2012;71(11):1914-5.

33. Zhang J, Xie F, Delzell E, Yun H, Lewis JD, Haynes K, et al. Impact of biologic agents with and without concomitant methotrexate and at reduced doses in older rheumatoid arthritis patients. Arthritis Care Res. 2015;67(5):624-32.

34. Fagerli KM, Lie E, van der Heijde D, Heiberg MS, Lexberg AS, Rodevand E, et al. The role of methotrexate co-medication in TNF-inhibitor treatment in patients with psoriatic arthritis: results from 440 patients included in the NOR-DMARD study. Ann Rheum Dis. 2014;73(1):132-7.

35. Heiberg MS, Koldingsnes W, Mikkelsen K, Rodevand E, Kaufmann C, Mowinckel $P$, et al. The comparative one-year performance of anti-tumor necrosis factor alpha drugs in patients with rheumatoid arthritis, psoriatic arthritis, and ankylosing spondylitis: results from a longitudinal, observational, multicenter study. Arthritis Rheum. 2008:59(2):234-40.

36. Kristensen LE, Gulfe A, Saxne T, Geborek P. Efficacy and tolerability of anti-tumour necrosis factor therapy in psoriatic arthritis patients: results from the South Swedish Arthritis Treatment Group register. Ann Rheum Dis. 2008;67(3):364-9.

37. Inc AV. Humira US Prescribing Information. 2013. http://www.accessdata.fda. gov/drugsatfda_docs/label/2013/125057s327lbl.pdf. Accessed 23 Dec 2015.

38. Nielsen $\mathrm{OH}$, Bjerrum JT, Herfarth $\mathrm{H}$, Rogler G. Recent advances using immunomodulators for inflammatory bowel disease. J Clin Pharmacol. 2013;53(6):575-88.

39. Shen DD, Azarnoff DL. Clinical pharmacokinetics of methotrexate. Clin Pharmacokinet. 1978;3(1):1-13.

40. Menting SP, Dekker PM, Limpens J, Hooft L, Spuls PI. Methotrexate dosing regimen for plaque-type psoriasis: a systematic review of the use of test-dose, start-dose, dosing scheme, dose adjustments, maximum dose and folic acid supplementation. Acta dermato-venereologica. 2015.
41. Vogelzang EH, Pouw MF, Nurmohamed M, Kneepkens EL, Rispens T, Wolbink GJ, et al. Adalimumab trough concentrations in patients with rheumatoid arthritis and psoriatic arthritis treated with concomitant disease-modifying antirheumatic drugs. Ann Rheum Dis. 2015;74(2):474-5.

42. Mrowietz U, Kragballe K, Reich K, Spuls P, Griffiths CE, Nast A, et al. Definition of treatment goals for moderate to severe psoriasis: a European consensus. Arch Dermatol Res. 2011;303(1):1-10.

\section{Submit your next manuscript to BioMed Central and we will help you at every step:}

- We accept pre-submission inquiries

- Our selector tool helps you to find the most relevant journal

- We provide round the clock customer support

- Convenient online submission

- Thorough peer review

- Inclusion in PubMed and all major indexing services

- Maximum visibility for your research

Submit your manuscript at www.biomedcentral.com/submit
C Biomed Central 